\title{
SECAGEM DE SPIRULINA SP. EM LEITO DE JORRO: EFEITO DA TEMPERATURA NAS CARACTERÍSTICAS DO PRODUTO DESIDRATADO
}

\author{
A. P. Q. LARROSA ${ }^{1}$, K. T. DA SILVA ${ }^{1}$, G. T. $\operatorname{LAMAS}^{1}$, V. P. SOARES ${ }^{1}$, L. A. A. PINTO \\ ${ }^{1}$ Universidade Federal do Rio Grande, Escola de Química e Alimentos \\ E-mail: anaquites@yahoo.com.br
}

\begin{abstract}
RESUMO - Neste trabalho foi avaliado a influência da temperatura do ar de secagem da Spirulina $s p$. em leito de jorro nas características do produto desidratado. A Spirulina sp LEB-18 foi cedida pelo laboratório de Engenharia Bioquímica (FURG), sendo cultivada em fotobiorreatores abertos em condições não controladas utilizando meio de cultivo Zarrouk. A secagem da biomassa foi realizada em leito de jorro de geometria cônica com $500 \mathrm{~g}$ de partículas de polietileno. Os experimentos foram avaliados em diferentes temperaturas do ar de entrada $\left(80,90,100\right.$ e $\left.110^{\circ} \mathrm{C}\right)$, sendo fixadas a vazão de alimentação e a concentração de sólidos da biomassa de $200 \mathrm{~mL} / \mathrm{h}$ e $5 \%(\mathrm{~m} / \mathrm{m})$, respectivamente. $\mathrm{O}$ produto foi avaliado quanto ao conteúdo de ficocianina, oxidação lipídica, compostos fenólicos e solubilidade proteica. A maior preservação da ficocianina e menor oxidação lipídica do produto foram observadas à temperatura de secagem de $80^{\circ} \mathrm{C}$. No entanto, os compostos fenólicos e a solubilidade proteica à temperatura de $100^{\circ} \mathrm{C}$ mostraram os melhores resultados.
\end{abstract}

\section{INTRODUÇÃO}

Spirulina sp. é uma microalga multicelular e filamentosa de coloração azulesverdeada, a qual vem sendo utilizada em muitos países na aquicultura, como alimento para consumo humano e animal, extração de pigmentos, produção de biocombustíveis, assim como, remoção de poluentes (Adiba et al., 2011; Thajuddin e Subramanian, 2005). A composição química desta microalga indica um elevado valor nutricional por possuir grande quantidade de nutrientes essenciais, tais como, provitaminas, minerais, proteínas e ácidos graxos poliinsaturados (ácido gama-linolenico) (Miranda et al., 1998).

Alguns estudos relatam que a Spirulina possui propriedades terapêuticas devido à presença de compostos antioxidantes, como os compostos fenólicos (Estrada et al., 2001; Miranda et al., 1998). Além disso, tem sido observado que a Spirulina é rica em ficobiliproteínas, nas quais se destaca a ficocianina, que é um pigmento utilizado em alimentos e que possui propriedades anti-inflamatórias e anti-cancerígenas (Reddy et al., 2003). 
A secagem é uma das alternativas mais utilizadas para conservação destas microalgas e preservação dos seus nutrientes. Assim, o estudo do efeito da temperatura do ar nas características do produto desidratado torna-se interessante. Além disso, na literatura existem poucos estudos relacionados ao efeito da secagem de microalgas nas características do produto final, sendo as principais técnicas avaliadas: spray drying, freeze drying (Ryckebosh et al., 2011) e secagem convectiva (Dissa et al., 2010, Oliveira et al., 2010).

A secagem em leito de jorro também tem sido pouco explorada em relação à secagem de microalgas (Oliveira et al., 2008). Além de ser um equipamento de baixo custo de operação e manutenção, tem sido empregado para secagem de pastas e suspensões de materiais termossensíveis, produzindo um pó fino com características similares ao pó obtido pelo spray dryer (Epstein e Grace, 2011). O leito de jorro apresenta um baixo tempo de residência do material dentro do leito em relação aos secadores de leito fixo, o que permite o uso de temperaturas de secagem mais elevadas.

Este trabalho teve como objetivo, avaliar o efeito da temperatura do ar na secagem da Spirulina em leito de jorro nas características do produto final, sendo considerados como resultados o conteúdo de ficocianina, a oxidação lipídica, os compostos fenólicos e a solubilidade proteica.

\section{MATERIAL E MÉTODOS}

\subsection{Matéria-Prima}

A matéria-prima utilizada neste trabalho foi a microalga Spirulina sp. LEB-18 cedida pelo Laboratório de Engenharia Bioquímica (FURG/RS). Esta microalga foi cultivada utilizando meio de cultivo Zarrouk em biorreatores, sob condições não controladas, segundo Morais et al. (2008). A biomassa foi prensada até $84 \%$ ( $\mathrm{m} / \mathrm{m}$, b.u.) de umidade, sendo após diluída até atingir a concentração de $5 \%(\mathrm{~m} / \mathrm{m})$ de sólidos.

\subsection{Secagem em Leito de Jorro}

A biomassa de Spirulina sp. foi seca em leito de jorro de geometria cônica com diâmetro de célula de $17,5 \mathrm{~cm}$. O diâmetro do orifício de entrada do ar era de 2,9 cm, e as bases de vidro inferior e superior apresentavam uma altura de $15 \mathrm{~cm}$ cada, com ângulo incluso de $60^{\circ}$. O ar de secagem foi aquecido por três resistências de $800 \mathrm{~W}$ cada, e a vazão do ar foi medida em placa de orifício. As temperaturas de entrada e saída do ar foram medidas por termopares do tipo cobre-constantan a cada 2 min e, após $30 \mathrm{~min}$, foram anotadas a cada intervalo de $5 \mathrm{~min}$.

O leito de partículas de inertes para a secagem da biomassa de Spirulina foi constituído por $500 \mathrm{~g}$ de partículas de polietileno, com diâmetro médio de $3,2 \mathrm{~mm}$, esfericidade de 0,7 e massa específica de $0,96 \mathrm{~g} / \mathrm{cm}^{3}$. A biomassa foi atomizada com ar comprimido utilizando uma pressão de $200 \mathrm{kPa}$ abs, sendo alimentada no leito a uma vazão 
de alimentação de $200 \mathrm{~mL} / \mathrm{h}$ por meio de uma seringa plástica de $50 \mathrm{~mL}$. A velocidade do ar foi de $100 \%$ acima da velocidade de jorro mínimo, como indicado para secagem de pastas e suspensões (Epstein e Grace, 2011). O produto desidratado foi recolhido em um recipiente de vidro acoplado a um ciclone tipo Lapple. Os experimentos foram realizados em diferentes temperaturas $\left(80,90,100\right.$ e $\left.110^{\circ} \mathrm{C}\right)$, e o seu efeito no produto desidratado foi avaliado quanto ao conteúdo de ficocianina, índice de ácido tiobarbitúrico (TBA), compostos fenólicos e solubilidade proteica.

\subsection{Metodologia Analítica}

\section{Composição Centesimal}

A biomassa in natura foi caracterizada através da composição centesimal pelas análises de umidade, cinzas e proteínas pela metodologia da AOAC (1995). A análise de lipídios foi determinada pelo método de Folch e Lee (1957). O teor de carboidratos foi determinado por diferença.

$\underline{\text { Ficocianina }}$

O conteúdo de ficocianina foi analisado utilizando método de Moraes et al. (2010), utilizando água como solvente extrator, e calculado segundo Bennett e Bogorad (1973).

\section{Índice de TBA}

A oxidação lipídica foi analisada pelo teste de TBA de acordo com a metodologia de Tibúrcio et al. (2007). O valor de TBA foi expresso como mg de malonaldeído (MDA) por $\mathrm{kg}$ de amostra, calculado através da curva padrão de tetrametoxipropano 0,01M com TBA.

\section{Compostos fenólicos}

Os compostos fenólicos foram determinados através da metodologia de Oliveira et al. (2004). A quantificação foi realizada pelo método espectrofotométrico utilizando o reagente Folin Ciocalteau a um comprimento de onda de $750 \mathrm{~nm}$. Foi utilizada uma curva padrão de ácido gálico e os valores foram quantificados em $\mathrm{mg}_{\mathrm{EAG}} / \mathrm{g}_{\text {amostra. }}$.

Solubilidade proteica (1985).

A solubilidade proteica em meio aquoso foi avaliada segundo o método de Morr

\subsection{Metodologia Estatística}

Os experimentos foram realizados em réplica, e as análises de composição centesimal (ficocianina, índice de TBA, compostos fenólicos e solubilidade proteica) foram realizadas em triplicata. Os resultados foram avaliados estatisticamente através do teste de Tukey ao nível de $95 \%$ de confiança $(\mathrm{p}<0,05)$. 


\section{RESULTADOS E DISCUSSÃO}

A Tabela 1 mostra a composição da biomassa de Spirulina in natura.

Tabela 1- Composição centesimal da biomassa de Spirulina.

\begin{tabular}{cc}
\hline Composição & $\begin{array}{c}\text { Spirulina in natura } \\
(\mathrm{g} / 100 \mathrm{~g}, \mathrm{~b} . \mathrm{s} .)^{*}\end{array}$ \\
\hline Proteína & $54,7 \pm 0,5$ \\
Lipídios & $18,0 \pm 0,2$ \\
Cinzas & $7,2 \pm 0,1$ \\
Carboidratos & $20,1 \pm 0,2$ \\
\hline
\end{tabular}

*Média \pm desvio padrão $(\mathrm{n}=3)$; b.s.: base seca

A Tabela 1 mostra a composição centesimal da biomassa de Spirulina, onde se pode observar que a microalga apresenta um elevado teor de proteína, o que está de acordo com a literatura (Oliveira et al., 2010).

O efeito da secagem da biomassa de Spirulina nas características do produto final foi analisado de acordo com a Tabela 2.

Tabela 2 - Caracterização físico-química e funcional das amostras in natura e secas em leito de jorro.

\begin{tabular}{ccccc}
\hline Amostra & $\begin{array}{c}\text { Ficocianina } \\
(\mathrm{mg} / \mathrm{g})^{*}\end{array}$ & $\begin{array}{c}\text { Índice de TBA } \\
\left(\mathrm{mg}_{\text {malonaldé́io }} / \mathrm{kg}_{\mathrm{amostra}}\right)^{*}\end{array}$ & $\begin{array}{c}\text { Compostos fenólicos } \\
\left(\mathrm{mg}_{\mathrm{EAG}} / \mathrm{g}_{\mathrm{amostra}}\right)^{*}\end{array}$ & $\begin{array}{c}\text { Solubilidade protéica } \\
(\%, \mathrm{~m} / \mathrm{m})^{*}\end{array}$ \\
\hline $80^{\circ} \mathrm{C}$ & $28,42 \pm 0,29^{\mathrm{a}}$ & $0,312 \pm 0,008^{\mathrm{a}}$ & $3,64 \pm 0,18^{\mathrm{a}}$ & $44,79 \pm 1,89^{\mathrm{a}}$ \\
$90^{\circ} \mathrm{C}$ & $12,21 \pm 0,21^{\mathrm{b}}$ & $0,340 \pm 0,004^{\mathrm{a}}$ & $4,41 \pm 0,07^{\mathrm{b}}$ & $39,99 \pm 1,77^{\mathrm{b}}$ \\
$100^{\circ} \mathrm{C}$ & $11,89 \pm 0,16^{\mathrm{b}}$ & $0,570 \pm 0,013^{\mathrm{b}}$ & $7,82 \pm 0,20^{\mathrm{c}}$ & $55,15 \pm 1,76^{\mathrm{c}}$ \\
$110^{\circ} \mathrm{C}$ & $10,59 \pm 0,06^{\mathrm{c}}$ & $0,646 \pm 0,137^{\mathrm{b}}$ & $7,15 \pm 0,22^{\mathrm{d}}$ & $35,58 \pm 2,25^{\mathrm{d}}$ \\
In & $29,1 \pm 0,22^{\mathrm{d}}$ & - & $8,52 \pm 0,40^{\mathrm{e}}$ & $28,42 \pm 0,29^{\mathrm{e}}$ \\
natura & - & & & \\
\hline
\end{tabular}

*Média \pm desvio padrão $(\mathrm{n}=2)$; $(\% \mathrm{~m} / \mathrm{m})$ : percentagem em massa. Letras diferentes na mesma coluna apresentam diferença significativa $(\mathrm{p}<0,05)$.

Analisando a Tabela 2, observa-se que cada resposta avaliada da microalga Spirulina na secagem em leito de jorro, mostrou diferentes comportamentos. O conteúdo de ficocianina da amostra in natura em relação aos experimentos de secagem apresentou diferença significativa ao nível de $95 \%$ ( $\mathrm{p}<0,05)$. Além disso, a secagem da biomassa diminuiu o teor de ficocianina nas amostras desidratadas, sendo que na menor temperatura $\left(80^{\circ} \mathrm{C}\right)$ apresentou menor degradação. Isso ocorreu devido à ficocianina ser um pigmento termossensível, sendo facilmente degradada pela ação de temperaturas elevadas. Estudos realizados por Oliveira $e t$ al. (2008), também foi observado uma diminuição da ficocianina na secagem em leito de jorro do tipo JSB em relação ao CSB, devido ao maior tempo de residência no leito. Antelo et al. (2008) também observou uma redução da ficocianina com temperaturas elevadas. 
Quanto ao índice de TBA, observa-se na Tabela 2 que o aumento da temperatura do ar provocou um aumento da oxidação lipídica das amostras desidratadas. Sendo que entre as menores temperaturas $\left(80-90^{\circ} \mathrm{C}\right)$ e entre as maiores temperaturas $\left(100-110^{\circ} \mathrm{C}\right)$ não foram apresentadas diferenças significativas $(\mathrm{p}>0,05)$. As menores alterações dos lipídios presentes nas amostras foram nos experimentos utilizando menores temperaturas do ar $\left(80\right.$ e $\left.90^{\circ} \mathrm{C}\right)$. Os resultados de ficocianina também apresentaram menores alterações na menor temperatura, mostrando que para essas respostas, a temperatura do ar de $80^{\circ} \mathrm{C}$ proporcionou melhores resultados em relação à preservação da ficocianina e menor oxidação lipídica.

Ao analisar os resultados de compostos fenólicos (Tabela 2), não foram observados os mesmos efeitos. Para os compostos fenólicos, o produto desidratado apresentou diferença significativa $(\mathrm{p}<0,05)$ em relação à amostra in natura, sendo que a secagem proporcionou perdas de 8 a 57\%. Além disso, as menores perdas destes compostos foram observadas nas maiores temperaturas do ar. Isso pode ter ocorrido, pois o tempo de contato com o ar quente influencia na liberação de compostos antioxidantes como os fenóis. Apesar da temperatura elevada do ar $\left(110^{\circ} \mathrm{C}\right)$, o tempo de residência do produto dentro do equipamento foi menor (12 min) do que na menor temperatura (16 min). Logo, este maior tempo de residência, mesmo em temperaturas mais baixas, pode ter afetado a liberação dos compostos bioativos e ocorrido alguma oxidação devido à maior exposição ao oxigênio presente. Segundo Wojdylo et al. (2009), as perdas de compostos fenólicos podem ser atribuídas à degradações oxidativa e térmica com os aumentos da intensidade e da extensão do tratamento térmico.

Com relação à solubilidade proteica em meio aquoso, observa-se na Tabela 2 um comportamento bem diferenciado das demais respostas, ou seja, um aumento de $10^{\circ} \mathrm{C}$ reduziu a solubilidade proteica de $80^{\circ} \mathrm{C}$ para $90^{\circ} \mathrm{C}$ e de 100 para $110^{\circ} \mathrm{C}$. Também, em relação à amostra in natura, a secagem proporcionou um aumento da solubilidade proteica ao nível de $95 \%$ de significância $(\mathrm{p}<0,05)$, sendo que na temperatura de $100^{\circ} \mathrm{C}$ foi apresentado melhor resultado. A solubilidade proteica é influenciada pelo tempo de exposição, assim como pela temperatura. Apesar de que, o produto coletado no secador está pouco acima da temperatura de bulbo úmido do ar de entrada $\left(35^{\circ} \mathrm{C}\right)$, e que as proteínas aumentam a sua solubilidade em temperaturas entre $40-50^{\circ} \mathrm{C}$, justifica o aumento da solubilidade proteica nas amostras desidratadas em relação à in natura. Segundo Desmoriex e Hernandez (2004), a perda do conteúdo de proteína foi proporcional com o aumento da temperatura de 40 a $70^{\circ} \mathrm{C}$ em secadores de bandeja.

\section{CONCLUSÃO}

A biomassa de Spirulina sp. foi avaliada na secagem em leito de jorro em diferentes temperaturas do ar de entrada nas características do produto final desidratado. Diante dos resultados, pode-se constatar que a temperatura de $80^{\circ} \mathrm{C}$ foi a mais adequada para preservar a ficocianina e evitar a oxidação dos ácidos graxos presentes na amostra. Porém, a temperatura de $100^{\circ} \mathrm{C}$ foi a mais adequada para os compostos antioxidantes, como os compostos fenólicos, assim como para a funcionalidade da proteína, como a solubilidade proteica. Com isso, 
percebe-se que dependendo da aplicação deste produto desidratado, a escolha da temperatura é um fator importante, a qual pode influenciar nas suas propriedades funcionais.

\section{AGRADECIMENTOS}

Os autores deste trabalho agradecem ao Laboratório de Engenharia Bioquímica pela matéria-prima e pela Capes pelo apoio financeiro.

\section{REFERÊNCIAS BIBLIOGRÁFICAS}

ADIBA, B. D.; SALEM, B.; NABIL, S.; ABDELHAKIM, M. Preliminary characterization of food tablets from date (Phoenix dactylifera L.) and spirulina (Spirulina sp.) powders. Powder Technol., v. 208, p. 725-730, 2011.

ANTELO, F. S.; COSTA, J. V.; KALIL, S. J. Thermal degradation kinetics of the phycocyanin from Spirulina platensis. Biochem. Eng. J., v. 41, p. 43-47, 2008.

AOAC. Official Methods of Analysis, 16th edn. Arlington, Virginia, USA: Association of Official Analytical Chemists, 1995.

BENNETT, A.; BOGORAD, L. Complimentary chromatic adaptation in a filamentous bluegreen alga. J. Cell Biol., v. 58, p. 419-435, 1973.

DESMORIEUX, H.; HERNANDEZ, F. Biochemical and physical criteria of Spirulina after different drying processes. In: Proceedings of the 14th International Drying Symposium (IDS), B, p. 900-907, 2004.

DISSA, A. O.; DESMORIEUX, H.; SAVADOGO, P. W.; SEGDA, B. G.; KOULIDIATI, J. Shrinkage, porosity and density behaviour during convective drying of Spirulina. J. Food Eng., v. 97, p. 410-418, 2010.

EPSTEIN, N.; GRACE, J. R. Spouted and Spout-fluid beds: Fundamentals and applications. New York: Cambridge University Press, 337p, 2011.

ESTRADA, J. E.; BESCÓS, P.; VILLAR DEL FRESNO, A. M. Antioxidant activity of diVerent fractions of Spirulina platensis protean extract. II Farmaco, v. 56, 497-500, 2001.

FOLCH, J.; LEES, M. A simple method for isolation and purification of total lipids from animal tissues. J. Biol. Chem., v. 226, p. 497-509, 1957.

MIRANDA, M. S.; CINTRA, R. G.; BARROS, S. B. M.; FILHO, J. M. Antioxidant activity of the microalga Spirulina maxima. Braz. J. Med. Biol. Res., v. 31, p. 1075-1079, 1998.

MORAES, C. C.; BURKERT, J. F. M.; KALIL, S. J. C-phycocyanin extraction process for large-scale use. J. Food Biochem., v. 34, p. 133-148, 2010.

MORAIS, M. G.; REICHERT, C. C.; DALCANTON, F.; DURANTE, A. J.; MARINS, L. F.; COSTA, J. A.V. Isolation and characterization of a new Arthrospira strain. Z. Naturforsch. V. 63c, p. 144, 2008.

MORR, C. V.; GERMAN, B.; KINSELA, J. E.; REGENSTEIN, J. M.; VAN-BUREN, J. P.; KILARA, A.; LEWIS, B. A.; MAGNINO, M. E. Collaborative study to develop a standardized food protein solubility procedure. J. Food Sci., v. 50, p. 1715-1718, 1985. 
OLIVEIRA, E. G.; ROSA, G. S.; MORAES, M. A.; PINTO, L. A. A. Phycocyanin contento f Spirulina platensis dried in spouted bed and thin layer. J. Food Process Eng., v. 31, p. 34-50, 2008.

OliVEIRA, E. G.; DUARTE, J. H.; MORAES, K.; CREXI, V. T.; PINTO, L. A. A. Optimisation of Spirulina platensis convective drying: evaluation of phycocyanin loss and lipid oxidation. Int. J. Food Sci.Technol., v. 45, p. 1572- 1578, 2010.

OLIVEIRA, M. S.; DORS, G. C.; SOUZA-SOARES, L. A.; BADIALE-FURLONG, E. Antifungal and antioxidant activity of vegetables extracts. Food Nutrition, v. 18, p.267275, 2007.

REDDY, M. C.; SUBHASHINI, J.; MAHIPAL, S. V. K.; BHAT, V. B.; REDDY, P. S.; KIRANMAI, G.; MADYASTHA, K. M.; REDDANNA, P. C-Phycocyanin, a selective cyclooxygenase-2 inhibitor, induces apoptosis in lipopolysaccharide- stimulated RAW 264.7 macrophages. Biochem. Biophys. Res. Commun., v. 304, p. 385-392, 2003.

RYCKEBOSCH, E.; MUYLAERT, K.; EECKHOUT, M.; RUYSSEN, T.; FOUBERT, I. Influence of drying and storage on lipid and carotenoid stability of the microalga Phaeodactylum tricornutum. J. Agric. Food Chem., v. 59, p. 11063-11069, 2011.

THAJUDDIN, N.; SUBRAMANIAN, G. Cyanobacterial biodiversity and potential application in biotechnology, Curr. Sci. India, v. 89, p. 47-57, 2005.

TIBURCIO, P. C.; GALVEZ, F. C. F.; CRUZ, L. J.; GAVINO, V. C. Optimization of lowcost drying methods to minimize lipid peroxidation in Spirulina platensis grown in the Philippines. J. Applied Phycol., v. 19, p. 719-726, 2007.

WOJDYLO, A.; FIGIEL, A.; OSZMIANSKI. Effect of drying methods with the application of vacuum microwaves on the bioactive compounds, color, and antioxidant activity of Strawberry Fruits. J. Agric. Food Chem., v. 57, p. 1337-1343, 2009. 